\title{
Biogeography Based Optimization Approach for Solving Optimal Power Flow Problem
}

\author{
Ouafa Herbadji, Linda Slimani and Tarek Bouktir \\ Dep. of Electrical Engineering, University of Setif 1, Setif, Algeria \\ tarek.bouktir@esrgroups.org
}

\begin{abstract}
This paper presents the use of a novel evolutionary algorithm called Biogeography-based optimization (BBO) for the solution of the optimal power flow problem. The objective is to minimize the total fuel cost of generation and environmental pollution caused by fossil based thermal generating units and also maintain an acceptable system performance in terms of limits on generator real and reactive power outputs, bus voltages, shunt capacitors/reactors and power flow of transmission lines. BBO searches for the global optimum mainly through two steps: Migration and Mutation. In the present work, BBO has been applied to solve the optimal power flow problems on IEEE 30-bus test system with six generating units to test the effectiveness of the proposed method. Satisfactory results obtained from the proposed method were compared to conventional and evolutionary optimization methods.
\end{abstract}

Keywords: Optimal Power Flow; Power Systems; Pollution Control; Biogeography Based Optimization (BBO)

\section{Introduction}

The optimal power flow (OPF) problem has been one of the most widely studied subjects in the power system community [1], he was first discussed by Carpentier in 1962 [2], the main purpose of OPF is to minimize the total thermal unit fuel cost, total emission, and total real power loss while satisfying physical and technical constraints on the network.

Oxides of nitrogen NOX emissions will be considered in the OPF problem for environmental protection. Power production from fossil burning and energy use may bring about significant adverse environmental effects through NOX emissions. So the total emission in the objective function will be considered in the OPF problem [3].

A wide variety of classical optimization techniques have been applied in solving the OPF problems considering a single objective function, such as nonlinear programming, quadratic programming, linear programming, Newton-based techniques, the sequential unconstrained minimization technique, interior point methods, and the parametric method.

As modern electrical power systems become more complex, planning, operation and control of such systems using conventional methods face increasing difficulties. Evolutionary methods have been developed and applied for solving problems in such complex power systems.

Biogeography-based optimization (BBO) is a novel evolutionary algorithm developed by Dan Simon in 2008 [4]. It is based on the mathematics of biogeography. Biogeography is the study of the geographical distribution of biological organisms. In the BBO model, problem solutions are represented as islands and the sharing of features between solutions. 
This paper exposes the $\mathrm{BBO}$ algorithm for solving multi-objective optimal power flow problem of IEEE 30-bus system. The simulation results of BBO algorithm are compared to the results of genetic algorithm GA [5], particle artificial bee colony algorithm ABC [6].

This paper is organized as follows; the problem formulation is presented in Section 2. The application of BBO into optimal power flow is discussed in Section 3. In Section 4, the case study including discussion is presented. Finally, conclusion is stated in Section5.

\section{Problem Formulation}

OPF is a static, nonlinear optimization problem, which calculates a set of optimum variables from the network state, load data and system parameters. Optimal values are computed in order to achieve a certain goal such as generation cost minimization or line transmission power loss minimization subject to equality and inequality constraints.

The standard OPF problem can be written in the following from:

$$
\min (\mathrm{F}(\mathrm{x}))
$$

subject to:

$$
\begin{aligned}
& g(x)=0 \\
& h(x) \leq 0
\end{aligned}
$$

where,

$\mathrm{F}(\mathrm{x})$ is the objective function.

$\mathrm{g}(\mathrm{x})$ is the equality constraints.

$\mathrm{h}(\mathrm{x})$ is the inequality constraints.

And $\mathrm{x}$ is the vector of control variables, the control variable can be generated active power $\mathrm{P}_{\mathrm{g}}$, generation bus magnitudes $\mathrm{V}_{\mathrm{g}}$, and transformers tap $\mathrm{T}$... etc.

$$
\mathrm{x}=\left[\mathrm{P}_{\mathrm{g}}, \mathrm{V}_{\mathrm{g}}, \mathrm{T} \ldots\right]
$$

\subsection{The objective function}

In this paper, the OPF problem is formulated as bi-objective optimization problem as follows:

\subsubsection{Minimization of fuel cost of power generation:}

Generally, the OPF problem can be expressed as minimizing the cost of production of the real power which is given by a quadratic function of generator power output $\mathrm{P}_{\mathrm{g}_{\mathrm{i}}}$ as $[7,8]$.

$\mathrm{F}=\sum_{\mathrm{i}=1}^{\mathrm{ng}} \mathrm{F}_{\mathrm{i}}=\sum_{\mathrm{i}=1}^{\mathrm{ng}}\left(\mathrm{A}_{\mathrm{i}}+\mathrm{B}_{\mathrm{i}} \mathrm{P}_{\mathrm{g}_{\mathrm{i}}}+\mathrm{C}_{\mathrm{i}} \mathrm{P}^{2} \mathrm{~g}_{\mathrm{i}}\right) \quad[\$ / \mathrm{h}]$

where:

$\mathrm{F}$ is The fuel cost function.

$A_{i}, B_{i}, C_{i}$ are the fuel cost coefficients. 
i represents the corresponding generator $(1,2, \ldots . . . n g)$.

$\mathrm{P}_{\mathrm{g}_{\mathrm{i}}}$ is the generated active power at bus $\mathrm{i}$.

ng is the number of generators including the slack bus.

\subsubsection{Minimization of polluted gas emission:}

The valve-point loading effect of thermal units is also taken into consideration; the total emission can be reduced by minimizing the three major pollutants: oxides of nitrogen (NOx), oxides of sulphur ( $\mathrm{SOx})$ and carbon dioxide $\left(\mathrm{CO}_{2}\right)$.

The objective function that minimizes the total emissions can be expressed in a linear equation as the sum of all the three pollutants resulting from generator real power [9].

The amount of NOx emission is given as a function of generator output (in Ton/h), that is, the sum of quadratic and exponential functions [10].

$\min \left(\mathrm{F}_{\mathrm{E}}\right)$

$\mathrm{F}_{\mathrm{E}}=\sum_{\mathrm{i}=1}^{\mathrm{ng}}\left(\mathrm{a}_{\mathrm{i}}+\mathrm{b}_{\mathrm{i}} \mathrm{P}_{\mathrm{g}_{\mathrm{i}}}+\mathrm{c}_{\mathrm{i}} \mathrm{P}^{2} \mathrm{~g}_{\mathrm{i}}+d_{i} \exp \left(e_{i} P_{g_{i}}\right)\right)\left[\frac{\text { Ton }}{h}\right]$

where; $F_{E}$ is the emission function. $a_{i}, b_{i}, c_{i}, d_{i}$ and $e_{i}$ are the coefficients of generators emission characteristic.

\subsection{The total objective function}

The total objective function considers at the same time the cost of the generation and the cost of pollution level control. However, the solutions may be obtained in which fuel cost and emission are combined in a single function with difference weighting factor.

This objective function is described by [11]:

$F_{\text {tot }}(x)=\alpha F+\beta F_{p c} \quad[\$ / h]$

where $\alpha$ is a weighting satisfies $0 \leq \alpha \leq 1$.

And $\beta=1-\alpha$

The pollution control cost (in $\$ / \mathrm{h}$ ) can be obtained by assigning a cost factor to the pollution level expressed as

$F_{p c}=w F_{E} \quad[\$ / h]$

where; $w$ the emission control cost factor [10].

\subsection{The equality and inequality constraints}

\subsubsection{The equality constraint}

The OPF equality constraints reflect the physics of the power system, equality constraints are expressed in the following equation:

$\sum_{\mathrm{i}=1}^{\mathrm{ng}} \mathrm{P}_{\mathrm{g}_{\mathrm{i}}}-\mathrm{P}_{\mathrm{D}}-\mathrm{P}_{\mathrm{L}}=0$

where; $\mathrm{P}_{\mathrm{D}}$ is the total power demand of the plant and $\mathrm{P}_{\mathrm{L}}$ is the total power losses of the plant. 


\subsubsection{The inequality constraints:}

The inequality constraints of the OPF reflect the limits on physical devices in the power system as well as the limits created to ensure system security that they are presented in the following inequalities:

- Upper and lower bounds on the active generations at generator buses

$$
\mathrm{P}_{\mathrm{g}_{\mathrm{i}}}^{\min } \leq \mathrm{P}_{\mathrm{g}_{\mathrm{i}}} \leq \mathrm{P}^{\max } \mathrm{g}_{\mathrm{i}}
$$

- Upper and lower bounds on the reactive power generations at generator buses and reactive power injection at buses with VAR compensation

$$
\mathrm{Q}_{\mathrm{g}_{\mathrm{i}}}^{\min } \leq \mathrm{Q}_{\mathrm{g}_{\mathrm{i}}} \leq \mathrm{Q}^{\max } \mathrm{g}_{\mathrm{i}}
$$

- Upper and lower bounds on the voltage magnitude at the all buses

$$
\mathrm{V}_{\mathrm{i}}^{\min } \leq \mathrm{V}_{\mathrm{i}} \leq \mathrm{V}^{\max _{\mathrm{i}}}
$$

- Upper and lower bounds on the bus voltage phase angles

$$
\theta_{\mathrm{i}}^{\min } \leq \theta_{\mathrm{i}} \leq \theta^{\max }{ }_{\mathrm{i}}
$$

- Upper and lower transformer tap setting $\mathrm{T}$ limits are set as:

$$
\mathrm{T}^{\min } \leq \mathrm{T} \leq \mathrm{T}^{\max }
$$

\section{BBO for Optimal Power Flow}

\subsection{Biogeography-based optimization (BBO)}

BBO is a new bio-inspired and population based optimization technique developed by Dan Simon in 2008[4]. It's similar to genetic algorithms (GA).

Mathematical models of BBO describe the migration of species from one island to another, how species arise and become extinct. Island in BBO is defined as any habitat that is isolated geographically from other habitats. Well suited habitats for species are said to have high habitat suitability index (HSI) while habitats that are not well suited said to have low HSI. Each habitat consists of features that decide the HSI for the habitat. These features are considered as independent variable and called suitability index variables (SIV) which map the value of the HSI of the habitat. High HSI habitats have large number of species while low HSI habitats have small number of species.

In $\mathrm{BBO}$, each individual has its own immigration rate $\lambda$ and emigration rate $\mu$. A good solution has higher $\mu$ and lower $\lambda$, vice versa. The immigration rate and the emigration rate are functions of the number of species in the habitat Figure 1. They can be calculated as follows:

$\lambda_{k}=I\left(1-\frac{k}{n}\right)$

$\mu_{k}=E\left(\frac{k}{n}\right)$

where I: is the maximum possible immigration rate. $\mathrm{E}$ is the maximum possible emigration rate. $\mathrm{k}$ is the number of species of the $k$ th individual in the ordered population according to the fitness. 


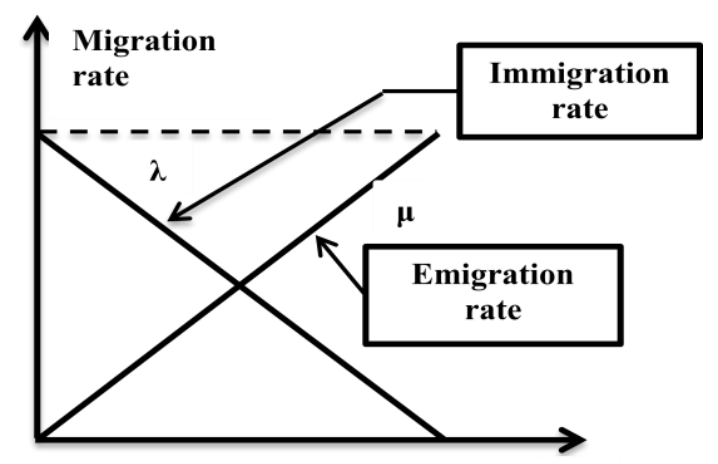

IS

Figure 1. Species model of a single habitat

There are two main operators, the migration and the mutation. One option for implementing the migration operator can be described as follow

\section{Main stages of Habitat migration}

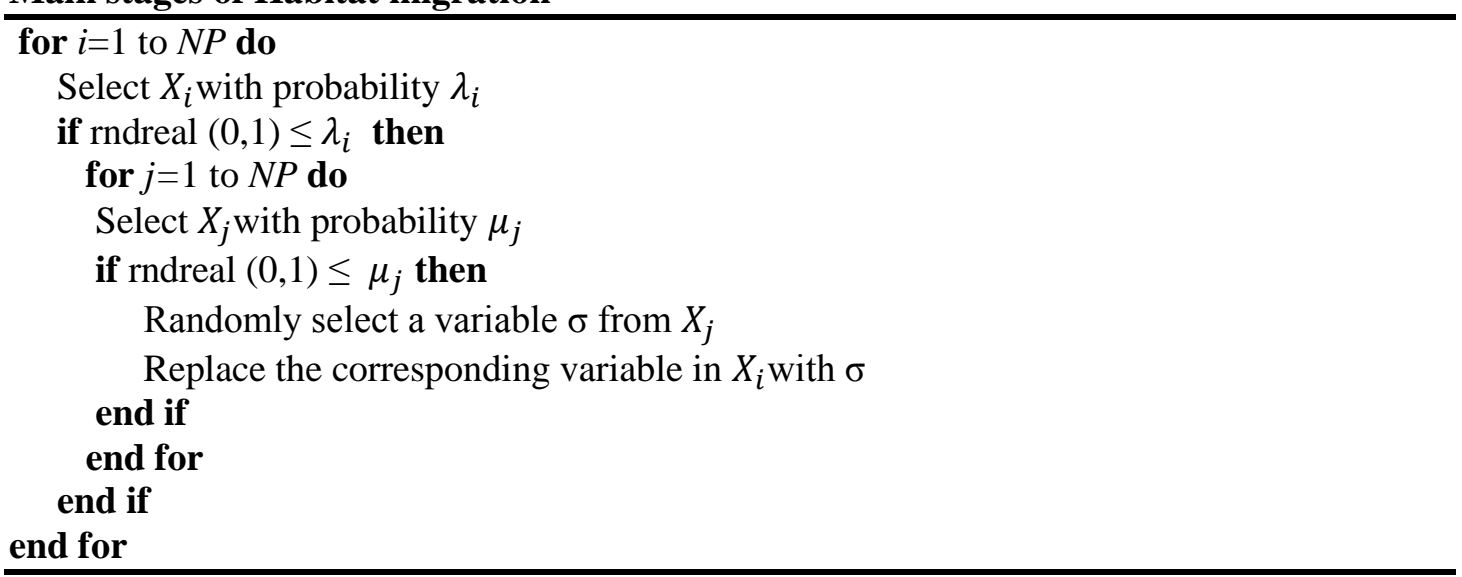

where; the population consists of $N P=n$ parameter vectors. rndreal $(0,1)$ is a uniformly distributed random real number in $(0,1)$ and $X i(j)$ is the $j^{\text {th }}$ SIV of the solution $X_{i}$

In BBO the mutation is modeled as SIV mutation using species count probabilities to determine mutation rate. Very high HSI and very low HSI solutions are likely to be mutated to a different solution using the mutation rate $\mathrm{m}$ that is calculated using

$m(s)=m_{\max }\left(1-\frac{P_{s}}{P_{\max }}\right)$

where $\mathrm{m}(\mathrm{s})$ is the mutation rate, $m_{\max }$ is the maximum mutation rate, Ps is the probability that $\mathrm{S}$ species in a habitat, and $P_{\max }$ is the maximum probability that $\mathrm{S}$ species in a habitat. When a solution is selected for mutation then we replace a randomly chosen SIV in the habitat with a new randomly generated SIV [11]. 


\subsection{BBO for optimal power flow}

In the economic dispatch problem each habitat represent a candidate solution consist of SIVs. Each SIV represents the output power generated by a specific generation unit and satisfying its different constrains.

1. Initialize BBO parameters.

2. Generate a random set of habitats that consists of SIVs representing feasible solutions.

3. Calculate HSI for all habitats and their corresponding rates $\mu$ and $\lambda$.

4. Identify the best solutions based on the HSI value and save the best solutions.

5. Probabilistically use $\lambda$ and $\mu$ to modify the non elite habitat using the migration process.

6. Based on species count probability of each habitat mutate the non-elite habitat then go to step (3).

7. After specified number of generation this loop is terminated.

After the modification of each habitat (steps 2, 5, 6) the feasibility of the habitat as a candidate solution should be tested and if it is not feasible then variables are tuned to convert it to a feasible solution [13].

\section{Application study}

The OPF using Biogeography Based Optimization (BBO) approach has been developed and implemented by the use of Matlab 9. The applicability and validity of this method (BBO) have been tested on IEEE 30-bus system with 6 generators $\left(\mathrm{n}^{\circ}: 1,2,5,8,11\right.$ and 13), 41 transmission lines and 4 transformers at line 11, 12, 15 and 36 Figure 2.

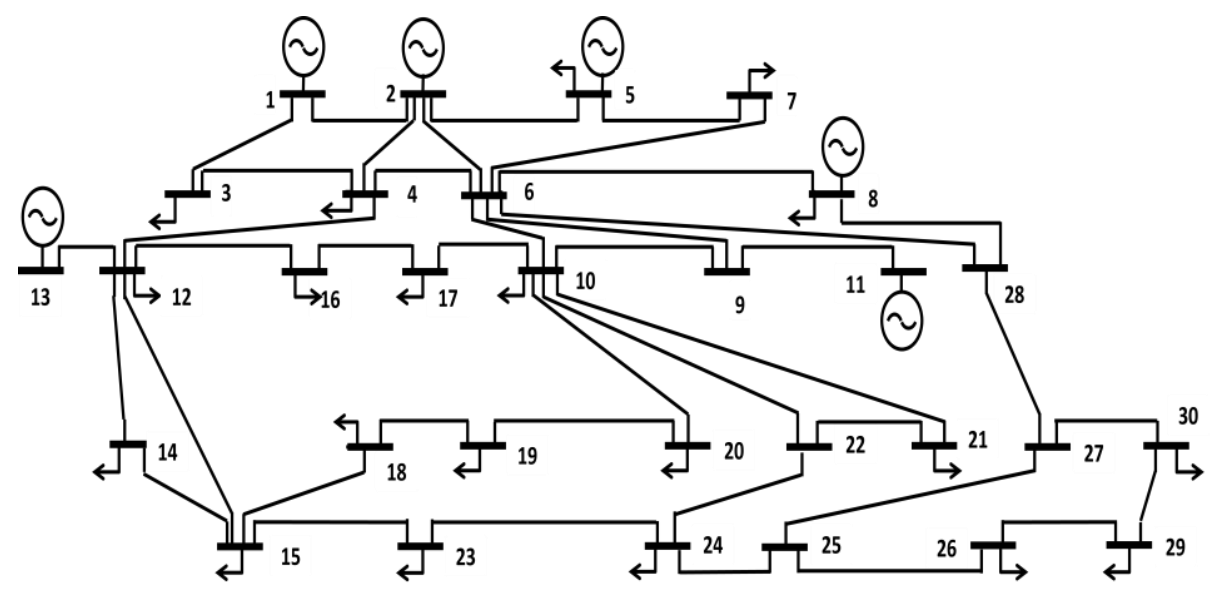

Figure 2. Structure of the tested IEEE 30 Bus System

Upper and lower active power generating limits and the unit costs of all generators of the IEEE 30-bus test system are presented in Table 1 [11], and the emission coefficients of generators are presented in Table 2 [14]. 
Table 1. Power generation limits and cost coefficients for IEEE 30-bus system

\begin{tabular}{|c|c|c|c|c|c|}
\hline Bus & $\begin{array}{l}\mathbf{P g}_{\text {imin }} \\
(\mathbf{M W})\end{array}$ & $\begin{array}{l}\mathbf{P g}_{\text {imax }} \\
(\mathbf{M W})\end{array}$ & $\begin{array}{l}A_{i} \\
(\$ / \mathbf{h r})\end{array}$ & $\begin{array}{l}B_{i} \cdot 10^{-2} \\
\text { (\$/MW.hr) }\end{array}$ & $\begin{array}{l}C_{i} \cdot 10^{-4} \\
\left(\$ \mathbf{M W}^{2} . \mathbf{h r}\right)\end{array}$ \\
\hline 1 & 50 & 200 & 0.00 & 200 & 37.5 \\
\hline 2 & 20 & 80 & 0.00 & 175 & 175.0 \\
\hline 5 & 15 & 50 & 0.00 & 100 & 625.0 \\
\hline 8 & 10 & 35 & 0.00 & 325 & 83.0 \\
\hline 11 & 10 & 30 & 0.00 & 300 & 250.0 \\
\hline 13 & 12 & 40 & 0.00 & 300 & 250.0 \\
\hline
\end{tabular}

Table 2. Emission coefficients for IEEE 30-bus system

\begin{tabular}{|l|l|l|l|l|l|}
\hline Bus & $\mathbf{a . 1 0}^{-2}$ & \multicolumn{1}{|c|}{$\mathbf{b . 1 0}^{-4}$} & $\mathbf{c . 1 0}^{-\mathbf{6}}$ & $\mathbf{d . 1 0}^{-4}$ & $\mathbf{e . 1 0}^{-2}$ \\
\hline $\mathbf{1}$ & 4.091 & -5.554 & 6.49 & 2.0 & 2.857 \\
\hline $\mathbf{2}$ & 2.543 & -6.047 & 5.638 & 5.0 & 3.333 \\
\hline $\mathbf{5}$ & 4.258 & -5.094 & 4.586 & 0.01 & 8.0 \\
\hline $\mathbf{8}$ & 5.326 & -3.55 & 3.38 & 20.0 & 2.0 \\
\hline $\mathbf{1 1}$ & 4.258 & -5.094 & 4.586 & 0.01 & 8.0 \\
\hline $\mathbf{1 3}$ & 6.131 & -5.555 & 5.151 & 10.00 & 6.667 \\
\hline
\end{tabular}

Upper and lower magnitude voltage limits are set between $0.95 \mathrm{pu} \& 1.1 \mathrm{pu}$, upper and lower bounds on the bus voltage phase angles are set between $-14^{\circ} \& 0^{\circ}$ and upper and lower transformer tap setting $\mathrm{T}$ limits are set between $0.95 \mathrm{pu} \& 1.1 \mathrm{pu}$. The total power demand is $283.4 \mathrm{MW}$ and the emission control cost factor $w$ is 550.66 \$/Ton [10].

The BBO properties in this simulation are set as follow:

- Population size: 20.

- Generation count limit: 200.

- Mutation probability: 0.01 .

- $\quad$ Maximum immigration rate: $\mathrm{I}=1$.

- Maximum emigration rate: $\mathrm{E}=1$.

A. In this part, the used control variables are only the actives power of generators.

$\mathrm{x}=\left[\mathrm{P}_{\mathrm{g}_{1}}, \mathrm{P}_{\mathrm{g}_{2}}, \mathrm{P}_{\mathrm{g}_{5}}, \mathrm{P}_{\mathrm{g}_{8}}, \mathrm{P}_{\mathrm{g}_{11}}, \mathrm{P}_{\mathrm{g}_{13}}\right]$

The results including the generation cost, and the power losses are shown in Table 3. A comparison with GA [5] and $\mathrm{ABC}[6]$ is also represented in this table. 
Table 3. Results of minimum fuel cost for IEEE 30-bus system

\begin{tabular}{lcll}
\hline Variables & BBO-OPF & ABC-OPF & GA-OPF \\
\hline $\mathbf{P g}_{1}$ (MW) & $\mathbf{1 7 1 . 9 2 3 1}$ & 180.5218 & 177.28 \\
$\mathbf{P g}_{\mathbf{2}}$ (MW) & $\mathbf{4 8 . 8 3 9 4}$ & 48.7845 & 48.817 \\
$\mathbf{P g}_{\mathbf{5}}$ (MW) & $\mathbf{2 1 . 4 3 9 1}$ & 21.2598 & 21.529 \\
$\mathbf{P g}_{\mathbf{8}}$ (MW) & $\mathbf{2 1 . 7 6 2 9}$ & 18.6469 & 21.81 \\
$\mathbf{P g}_{11}$ (MW) & $\mathbf{1 2 . 1 8 3 1}$ & 11.8145 & 11.325 \\
$\mathbf{P g}_{13}$ (MW) & $\mathbf{1 6 . 5 5 8 8}$ & 12.1011 & 12.087 \\
\hline Ploss $(\mathbf{M W )}$ & $\mathbf{9 . 3 0 6 4}$ & 9.7286 & 9.4563 \\
\hline Production cost & $\mathbf{8 0 2 . 7 1 7}$ & 802.1649 & 802.0012 \\
(\$/hr) & & & \\
\hline
\end{tabular}

The active powers of the 6 generators as shown in this table are all in their allowable limits. We can observe that the BBO gives an acceptable solution (802.717 compared with 802.1649 and 802.0012$)(\$ / \mathrm{h})$ and it is as good as GA and ABC in solving the optimal power flow.

Figure 3 shows the typical convergence characteristics for the best solutions of the minimum fuel cost obtained for each generation. It can be seen that the convergence is fast for the proposed BBO.

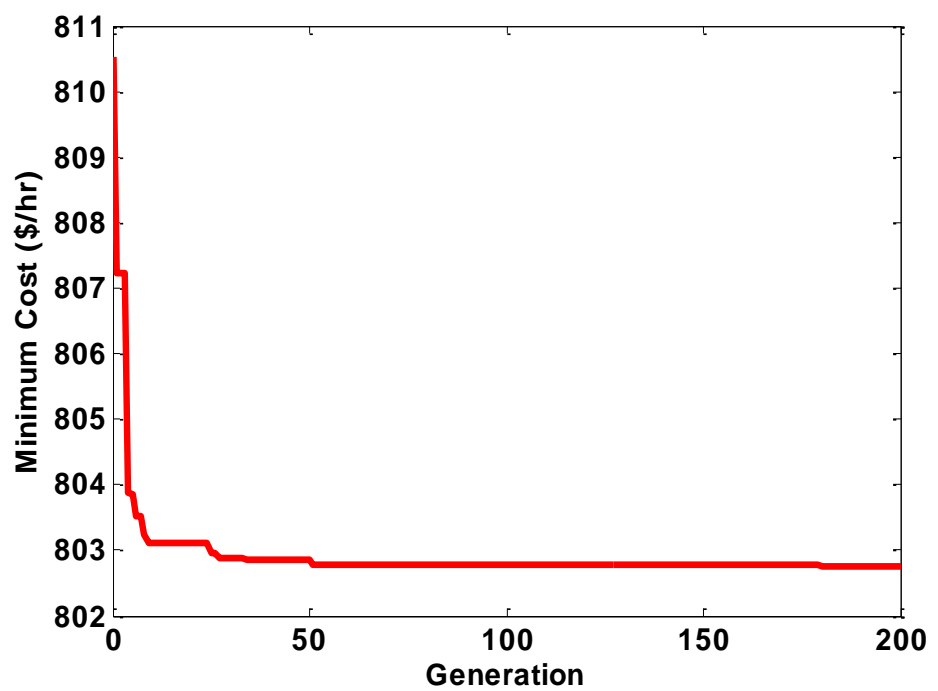

Figure 3. The convergence profile of BBO-based OPF solutions for IEEE 30-bus system

$\boldsymbol{B}$. In this part the vector of control variables include the generated active powers, magnitude voltages of generators and transformer tap settings.

$x=\left[P_{g_{1}}, P_{g_{2}}, P_{g_{5}}, P_{g_{8}}, P_{g_{11}}, P_{g_{13}}, V_{1}, V_{2}, V_{5}, V_{8}, V_{11}, V_{13}, T_{6-9}, T_{6-10}, T_{4-12}, T_{28-27}\right]$

The results including the generation cost, the emission level, total cost, generated active power, magnitude voltage and power losses are shown in Table 4. 
Table 4. The optimum generations for minimum total cost obtained by BBO

\begin{tabular}{|c|c|c|c|c|}
\hline & $\alpha=1$ & $\alpha=0.9$ & $\alpha=0.8$ & $\alpha=0.7$ \\
\hline $\mathbf{P g}_{1}(\mathrm{MW})$ & 176.2752 & 168.3324 & 159.2350 & 149.3395 \\
\hline $\mathbf{P g}_{2}(\mathrm{MW})$ & 50.6279 & 50.2112 & 50.6279 & 53.2520 \\
\hline $\mathbf{P g}_{5}(\mathrm{MW})$ & 21.0016 & 21.8593 & 21.5001 & 23.2944 \\
\hline $\mathbf{P g}_{8}(\mathrm{MW})$ & 20.5166 & 24.9656 & 29.2399 & 31.3826 \\
\hline $\mathbf{P g}_{11}(\mathrm{MW})$ & 11.7012 & 14.0621 & 15.8029 & 17.7903 \\
\hline $\mathrm{Pg}_{13}(\mathrm{MW})$ & 12.1978 & 12.6650 & 14.7395 & 15.5836 \\
\hline $\mathrm{Vg}_{1}(\mathrm{pu})$ & 1.0985 & 1.0990 & 1.0986 & 1.0981 \\
\hline $\mathrm{Vg}_{2}(\mathrm{pu})$ & 1.0828 & 1.0793 & 1.0815 & 1.0889 \\
\hline$V g_{5}(p u)$ & 1.0617 & 1.0521 & 1.0451 & 1.0638 \\
\hline $\mathrm{Vg}_{8}(\mathrm{pu})$ & 1.0748 & 1.0310 & 1.0633 & 1.0742 \\
\hline $\mathrm{Vg}_{11}(\mathrm{pu})$ & 1.0954 & 1.0765 & 1.0926 & 1.0983 \\
\hline $\operatorname{Vg}_{13}(p u)$ & 1.0877 & 1.0773 & 1.0847 & 1.0508 \\
\hline Ploss (MW) & 8.9203 & 8.6957 & 7.7454 & 7.2423 \\
\hline $\begin{array}{l}\text { Production cost } \\
(\$ / h)\end{array}$ & 800.1091 & 802.0843 & 802.8280 & 806.6112 \\
\hline Emission (ton/h) & 0.3665 & 0.3450 & 0.3236 & 0.3032 \\
\hline Total cost $(\$ / h)$ & 1001.926 & 992.062 & 981.021 & 973.5713 \\
\hline Variable & $\alpha=0.6$ & $\alpha=0.5$ & $\alpha=0.4$ & $\alpha=0.3$ \\
\hline $\mathbf{P g}_{1}(\mathrm{MW})$ & 141.0415 & 130.1453 & 121.2426 & 114.6278 \\
\hline Pg2 (MW) & 54.4719 & 58.5889 & 59.5648 & 62.2191 \\
\hline Pg5 (MW) & 24.6160 & 25.5835 & 26.8616 & 29.9439 \\
\hline Pg8 (MW) & 33.9511 & 34.8999 & 33.7020 & 28.4166 \\
\hline Pg11 (MW) & 18.2054 & 20.8860 & 26.0472 & 29.7159 \\
\hline $\operatorname{Pg13}$ (MW) & 17.7838 & 19.5026 & 21.7430 & 24.0662 \\
\hline Vg1 (pu) & 1.0963 & 1.0947 & 1.0908 & 1.0971 \\
\hline $\mathrm{Vg}_{2}(\mathrm{pu})$ & 1.0869 & 1.0907 & 1.0752 & 1.0860 \\
\hline$V_{g_{5}}(p u)$ & 1.0614 & 1.0567 & 1.0542 & 1.0565 \\
\hline $\mathrm{Vg}_{8}(\mathrm{pu})$ & 1.0738 & 1.0654 & 1.0674 & 1.0766 \\
\hline$V_{g_{11}}(p u)$ & 1.0951 & 1.0946 & 1.0862 & 1.0974 \\
\hline $\mathrm{Vg}_{13}(\mathrm{pu})$ & 1.0894 & 1.0918 & 1.0898 & 1.0848 \\
\hline Ploss(MW) & 6.6696 & 6.2062 & 5.7611 & 5.5894 \\
\hline $\begin{array}{l}\text { Production cost } \\
(\$ / h)\end{array}$ & 810.4879 & 818.0145 & 827.0046 & 838.0996 \\
\hline Emission (ton/h) & 0.2883 & 0.2713 & 0.2580 & 0.2497 \\
\hline Total cost $(\$ / h)$ & 969.243 & 967.4085 & 969.0748 & 975.5994 \\
\hline Variable & $\alpha=0.2$ & & & $\alpha=0$ \\
\hline$\overline{P g_{1}(M W)}$ & 95.7621 & 85.0 & & 69.7828 \\
\hline $\mathrm{Pg}_{2}(\mathrm{MW})$ & 65.8134 & & & 70.0270 \\
\hline $\mathrm{Pg}_{5}(\mathrm{MW})$ & 35.2727 & & & 49.5173 \\
\hline
\end{tabular}




\begin{tabular}{|c|c|c|c|}
\hline $\mathrm{Pg}_{8}(\mathrm{MW})$ & 34.8146 & 34.8146 & 34.8979 \\
\hline $\operatorname{Pg}_{11}(\mathbf{M W})$ & 29.5469 & 29.7080 & 29.9131 \\
\hline $\operatorname{Pg}_{13}(\mathbf{M W})$ & 26.7871 & 30.2455 & 32.9636 \\
\hline $\mathrm{Vg}_{1}(\mathrm{pu})$ & 1.0944 & 1.0816 & 1.0283 \\
\hline $\mathrm{Vg}_{2}(\mathrm{pu})$ & 1.0850 & 1.0699 & 1.0233 \\
\hline $\mathrm{Vg}_{5}(\mathrm{pu})$ & 1.0419 & 1.0515 & 1.0037 \\
\hline $\mathrm{Vg}_{8}(\mathrm{pu})$ & 1.0682 & 1.0624 & 1.0092 \\
\hline $\operatorname{Vg}_{11}(\mathbf{p u})$ & 1.0984 & 1.0984 & 1.0977 \\
\hline $\mathrm{Vg}_{13}(\mathrm{pu})$ & 1.0934 & 1.0834 & 1.0927 \\
\hline Ploss(MW) & 4.5967 & 4.0212 & 3.7017 \\
\hline Production cost $(\$ / \mathrm{hr})$ & 861.8924 & 890.0276 & 930.6462 \\
\hline Emission (ton/h) & 0.2318 & 0.2235 & 0.2178 \\
\hline Total cost $(\$ / h)$ & 989.5353 & 1013.1001 & 1050.5799 \\
\hline
\end{tabular}

This table gives the optimum generations for minimum total cost in three cases with 11 values of $\alpha$ :

Case 1: minimum generation cost without using into account the emission level as the objective function $(\alpha=1)$.

Case 2: minimum generation cost with using into account the emission level as the objective function $(0 \leq \alpha \leq 1)$

Case 3: a total minimum emission is taken as the objective of main concern $(\alpha=0)$.

The active powers of the 6 generators as shown in this table are all in their allowable limits. We can observe that the total cost of generation and pollution control is the highest at the minimum emission level $(\alpha=0)$ with the lowest real power loss $(3.7017 \mathrm{MW})$. The difference in generation cost between the case 1 and the case $3(800.1091 \$ / \mathrm{h}$ compared to 930.6462 $\$ / \mathrm{hr}$ ), in real power loss (8.9203MW compared to $3.7017 \mathrm{MW}$ ) and in emission level $(0.3665 \mathrm{Ton} / \mathrm{h}$ compared to $0.2178 \mathrm{Ton} / \mathrm{hr})$ clearly shows the trade-off. To decrease the generation cost, one has to sacrifice some of environmental constraint. The Figure 4 shows the total cost for different values of $\alpha$. Obtained by BBO. This figure shows that the minimum total cost is at $\alpha=0.5$ with value of $967.4085 \$ / h$ 


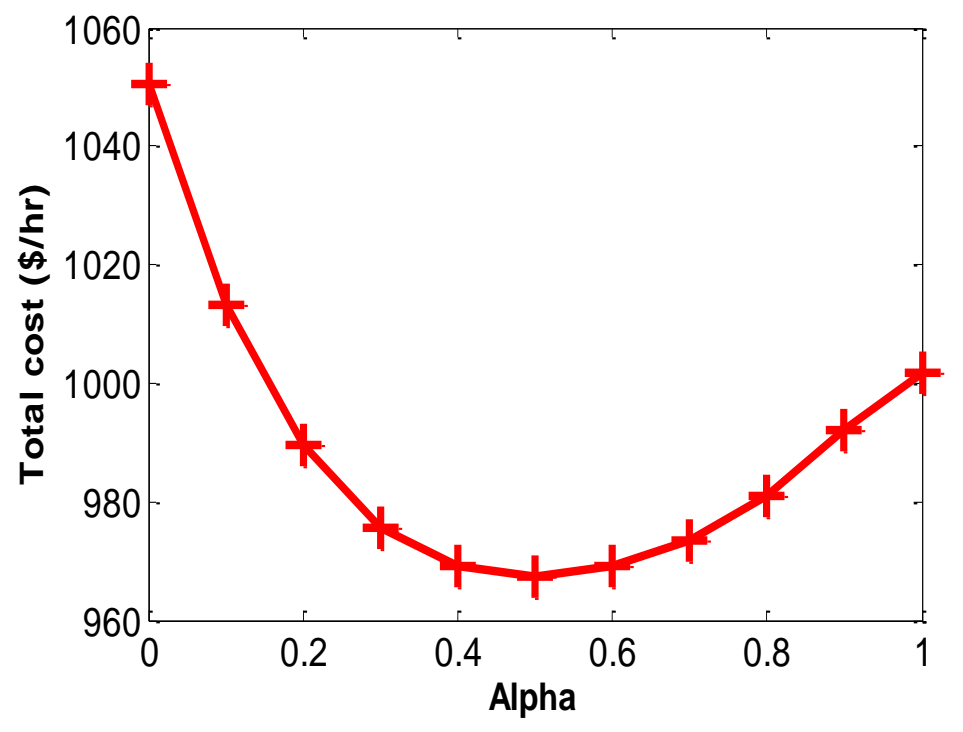

Figure 4. The optimum total cost for different values of $\alpha$ obtained by BBO

The results including the voltage magnitude and the angles of three values of $\alpha$ are exposed in Figure 5 and Figure 6 respectively.

We can observe that all voltage magnitudes and the angles of IEEE 30-bus system are between their minimum and maximum values.

The comparison of the results obtained by the proposed approach with those found artificial bee colony algorithm $\mathrm{ABC}[15]$ are reported in the Table 5.

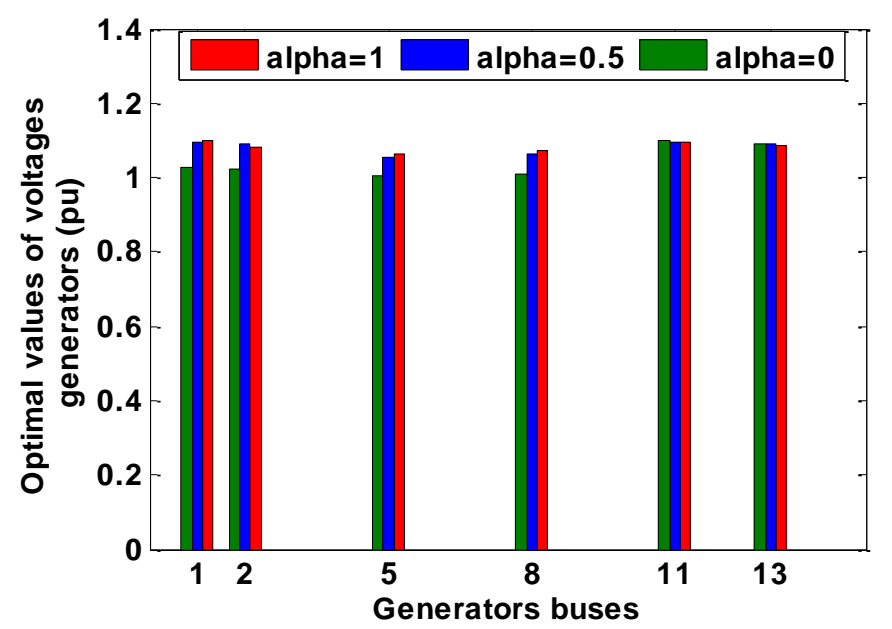

Figure 5. The values of voltages generators at three value of $\alpha$ (p.u) obtained by BBO 


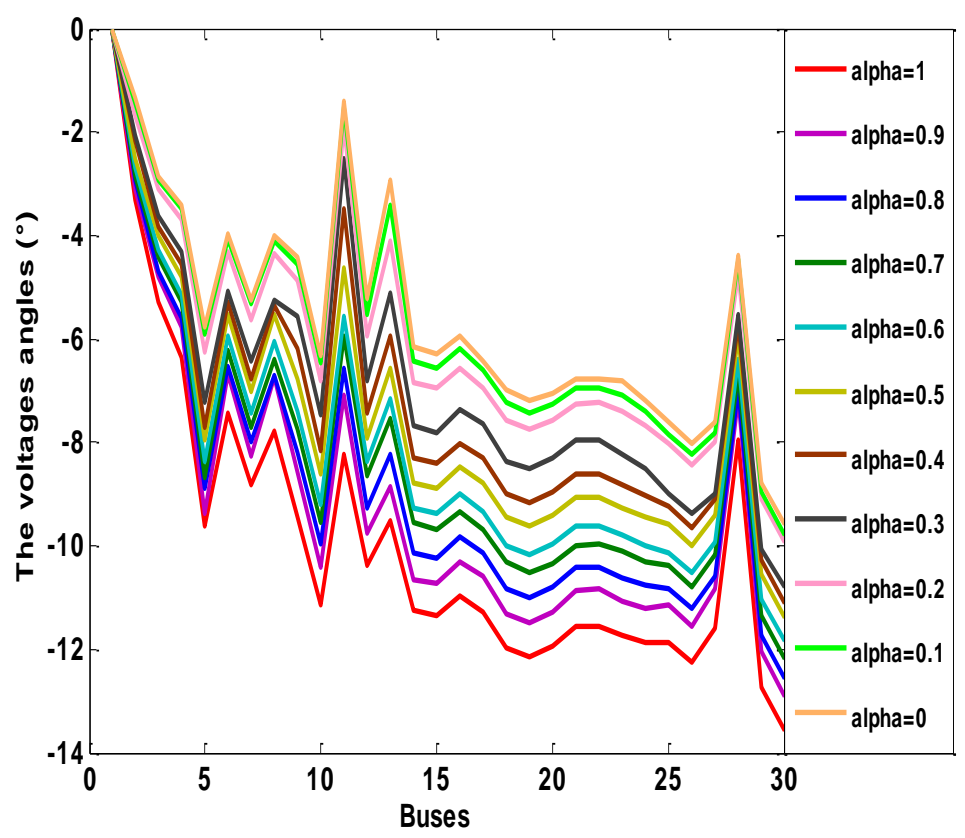

Figure 6. The results of the voltage angles $\left({ }^{\circ}\right)$ at 11 values of $\alpha$ obtained by BBO

This table gives the optimum generations for minimum total cost in three cases: minimum generation cost without using into account the emission level as the objective function $(\alpha=1)$, an equal influence of generation cost and pollution control in this function and at last a total minimum emission is taken as the objective of main concern $(\alpha=0)$.

Table 5. Comparisons of results obtained by $B B O$ and $A B C$ for minimum total cost in three cases of $\alpha$

\begin{tabular}{ccc}
\hline $\begin{array}{c}\text { Production cost } \\
(\mathbf{\$} / \mathbf{h})\end{array}$ & Emission (ton/h) & Total cost $\mathbf{( \$ / h )}$ \\
\hline 800.1091 & 0.3665 & 1001.926 \\
800.9275 & 0.3712 & 1005.3324 \\
\hline 818.0145 & 0.2713 & 967.4085 \\
819.997 & 0.2701 & 968.7302 \\
\hline 930.6462 & 0.2178 & 1050.5799 \\
934.126 & 0.2174 & 1053.8394 \\
\hline
\end{tabular}

The comparison between $\mathrm{BBO}$ and $\mathrm{ABC}$ show that the Biogeography-based optimization gives acceptable solution in the three cases. 
The BBO gives more important results of fuel cost $(800.1091 \$ / \mathrm{hr}, 818.0145 \$ / \mathrm{h} \&$ $930.6462 \$ / \mathrm{hr}$ ) compared with the results obtained with ABC method $(800.9275 \$ / \mathrm{h}$, $819.997 \$ / \mathrm{h} \& 934.126 \$ / \mathrm{h}$ ) and in the emission level also.

We consider two cases of optimization. In the first case, the control vector represents only the generator active power outputs. However in the second case, the vector represents the generator active power outputs, magnitude voltage and transformers tap-setting. The results give significant reductions in cost and losses for the second case (Power losses: 8.9203MW) compared to the first one (9.3064 MW).

\section{Conclusion}

In this paper, the Biogeography-based optimization $\mathrm{BBO}$ has been successfully implemented to solve optimal power flow problem for minimization of the cost of the generation, the cost of pollution level control and the active power loss. This approach has been tested and examined on both IEEE 30-bus test systems to demonstrate its effectiveness. The comparisons of the results obtained by $\mathrm{BBO}$ with those found by the genetic algorithm GA and artificial bee colony algorithm ABC gives acceptable solution and he is as good as $\mathrm{GA}$ and $\mathrm{ABC}$ in solving the optimal power flow.

\section{References}

[1] H. Wang, C. E. Murillo-Sanchez, R. D. Zimmerman and R. J. Thomas, "On Computational Issues of MarketBased Optimal Power Flow", IEEE Transactions on Power Systems, vol. 22, no. 3, (2007) August, pp. 11851193.

[2] J. Carpentier, "Contribution a l'étude du dispatching économique", Bulletin de la Société Française des Electriciens, vol. 3, (1962) August, pp. 431-447.

[3] R. -H. Liang, S. -R. Tsai, Y. -T. Chen and W. -T. Tseng, "Optimal power flow by a fuzzy based hybrid particle swarm optimization approach", Electric Power Systems Research, vol. 81, (2011), pp. 1466-1474.

[4] D. Simon, "Biogeography-Based Optimization", IEEE Transaction on Evolutionary Computation, vol. 12, no. 6, (2008) December, pp. 702-713.

[5] T. Bouktir, L. Slimani and M. Belkacemi, "A Genetic Algorithm for Solving the Optimal Power Flow Problem", Leonardo Journal of Sciences, (2004).

[6] L. Slimani and T. Bouktir, "Optimal Power Flow with Emission Controlled using Artificial Bee Colony Algorithm", 12th International conference on Sciences and Techniques of Automatic control \& computer engineering, (2011), Sousse, Tunisia.

[7] A. J. Wood and B. F. Wollenberg, "Power Generation, Operation and Control", 2nd Edition, John Wiley (1996).

[8] G. W. Stagg and A. H. El Abiad, "Computer methods in power systems analysis", McGraw-Hill, (1981).

[9] L. Slimani and T. Bouktir, "Economic Power Dispatch of Power System with Pollution Control using Multiobjective Ant Colony Optimization", International Journal of Computational Intelligence Research., ISSN 0973-1873, vol. 3, no. 2, (2007), pp. 145-153.

[10] B. Mahdad, T. Bouktir and K. Srairi, "OPF with Environmental Constraints with Multi Shunt Dynamic Controllers using Decomposed Parallel GA: Application to the Algerian Network", Journal of Electrical Engineering \& Technology, vol. 4, no. 1, (2009), pp. 55-65.

[11] T. Bouktir and M. Belkacemi, "Object-Oriented Optimal Power Flow", Electric Power Components and systems, vol. 31, no. 6, (2003), pp. 525-534.

[12] A. Bhattacharya and P. K. Chattopadhyay, "Biogeography-Based Optimization for Different Economic Load Dispatch Problems", IEEE Trans. On Power Syst., vol. 25, no. 2, (2010) May, pp. 1064-1075.

[13] Z. Mohammed and J. Talaq, "Economic Dispatch by Biogeography Based Optimization Method", International Conference on Signal, Image Processing and Applications With workshop of ICEEA 2011, IPCSIT, vol. 21, (2011). 
[14] T. Bouktir, R. Labdani and L. Slimani, "Economic Power Dispatch of Power System with Pollution Control using Multiobjective Particle Swarm Optimization", Journal of Pure \& Applied Sciences, vol. 4, no. 2, (2007), pp. 57-77.

[15] S. Mouassa and T. Bouktir, "Multiobjective Artificial Bee Colony Algorithm for Economic/Emission Optimal Power Flow problem", International conference on information processing and electrical engineering, ICIPEE12, Algeria, (2012).

\section{Authors}

\section{Ouafa Herbadji}

She was born in Setif, Algeria in 1987. She received the engineering degree in electrical engineering from Setif University (Algeria) in 2010. Currently she is a student in the third year of magister in Setif University, Algeria. His area of interest is the application of the meta-heuristic methods in power systems analysis.

\section{Dr. Linda Slimani}

She received the $\mathrm{PhD}$ degree in power system in 2009. His area of interest is the application of the metaheuristique methods in Power systems Analysis. Currently she serves as associate professor at the Department of Electrical Engineering in Setif 1 University (Setif), ALGERIA.

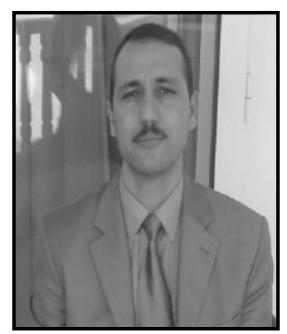

\section{Prof. Tarek BOUKTIR}

He was born in Ras El-Oued, Algeria in 1971. He is the Editor-InChief of Journal of Electrical Systems (Algeria), the Co-Editor of Journal of Automation \& Systems Engineering (Algeria). He is with the Department of Electrical Engineering in Setif 1 University, ALGERIA. He currently serves as a member of the Board of the University of setif 1 . 